\title{
COMMUNICATIONS
}

\section{Introduction of ${ }^{15} \mathrm{~N}$ into Proteins of the Rat}

By P. Fürst, B. Josephson and B. Philipson (Department of Clinical Chemistry, St. Erik's Hospital, and Department of Ophthalmology, Carolinian Hospital, Stockholm, Sweden)

$\left[{ }^{15} \mathrm{~N}\right]$ Ammonium acetate was given intraperitoneally to rats and intravenously to rabbits. The rats were killed after 1-8 days and the $\%{ }^{15} \mathrm{~N}$ atoms excess was determined in muscle, liver and lens protein and in non-protein N. From the rabbits muscle samples were obtained by surgery in anaesthesia several times during 12 days simultaneously with the drawing of blood samples.

${ }^{15} \mathrm{~N}$ incorporation was initially much higher in liver and plasma protein than in muscle protein, and decreased more slowly in muscle protein. Except for the first samples after administration the degree of incorporation was similar in protein and in nonprotein $\mathbf{N}$ in both species in liver and in muscle, indicating an equilibrium of ${ }^{15} \mathrm{~N}$ between cell protein and intracellular free amino acids.

In the lens, on the other hand, very little ${ }^{15} \mathrm{~N}$ was recovered in the protein, whereas incorporation was high in lens non-protein N. This latter incorporation decreased rapidly but remained much higher than in the lens protein. This indicates a very slow turnover of the lens proteins.

\section{Effect of Plane of Nutrition on Maternal and Foetal Plasma Amino Acid Concentrations in the Sheep}

By John S. Slater and David J. Mellor (Moredun Research Institute, 408 Gilmerton Road, Edinburgh EH17 7JH, U.K)

Decrease of dietary protein in non-pregnant sheep increased the plasma concentration ratio of nonessential to essential amino acids (Leibholz, 1970). In pregnancy, foetal development may be influenced if similar changes are reflected in foetal plasma. However, individual amino acids show typical distributions between foetal and maternal plasma, apparently resulting from active transport across the placenta, which may in part regulate foetal plasma concentrations (Hopkins et al., 1971a,b).

Two groups of six pregnant Scottish Blackface ewes were maintained on high and low planes of general nutrition from 8 weeks post-conception to term (21 weeks). Each low-plane sheep received $25 \mathrm{~g}$ and each high-plane sheep $130-200 \mathrm{~g}$ of crude protein/ day.

Plasma concentrations of total protein were significantly lower in low-plane than in high-plane ewes from
12 weeks gestation, and urea concentrations were lower in the low-plane group throughout. Although total amino acid concentrations were not significantly different at any stage and showed no trends during pregnancy, a progressive and significant increase in the plasma concentration ratio of non-essential to essential amino acids occurred in low-plane sheep by 20 weeks (ranges: low-plane sheep, 1.7-2.9; highplane sheep, 1.3-1.7), with particular decreases in threonine, valine, leucine and phenylalanine concentrations. Glycine and glutamine concentrations were elevated. Concentrations of arginine, ornithine and citrulline were considerably lower in low-plane sheep throughout.

Foetal plasma composition was examined in two low-plane and one high-plane sheep. At 117 (lowplane sheep), 122 (low-plane sheep) and 132 (highplane sheep) days' gestation, the uterine and umbilical vasculatures were catheterized (Mellor \& Slater, 1971) and daily samples of foetal and maternal blood were obtained for 27, 21 and 11 days respectively. Acute preparations were not used because pre-operative starvation, pentobarbitone anaesthesia and surgical stress alter maternal and foetal plasma amino acid concentrations (E. J. Hervey \& J. S. Slater, unpublished work).

Foetal plasma concentration ratios of non-essential to essential amino acids (ranges: low-plane sheep, 1.9-2.9; high-plane sheep, 1.1-1.2) were affected similarly to those in maternal plasma, but with substantially higher serine concentrations in the lowplane foetuses. These changes may be relevant to the differential effects of low protein intakes on organ and tissue composition of lambs (Sykes \& Field, $1972 a$ ), but should be investigated in relation to the energy available for foetal growth.

In the low-plane ewes, foetal to maternal plasma concentration ratios of most amino acids, both essential and non-essential, were higher or similar to those in the high-plane ewe, which suggests that at the low plane of nutrition the foetus received a relatively higher proportion of available amino acids. This agrees with the suggestion by Sykes \& Field $(1972 b)$ that at low protein intakes the efficiency of protein conversion for foetal growth may be improved.

Hopkins, L., McFadyen, I. R. \& Young, M. (1971a) J. Physiol. (London) 215, 9P-10P

Hopkins, L., McFadyen, I. R. \& Young, M. (1971b) J. Physiol. (London) 115, $11 P-12 P$

Leibholz, J. (1970) Aust. J. Agr. Res. 21, 723-734

Mellor, D. J. \& Slater, J. S. (1971) J. Physiol. (London) 217, 573-604

Sykes, A. R. \& Field, A. C. (1972a) J. Agr. Sci. 78, 119-125

Sykes, A. R. \& Field, A. C. (1972b) J. Agr. Sci. 78, 127-133 